\title{
Optimization of ultrasound- assisted aqueous extraction to produce virgin avocado oil with low free fatty acids
}

\begin{abstract}
Virgin avocado oil has been suggested to be used as functional oil due to its high nutritional value. The quality and edibility of plant oils are affected by the level of free fatty acids (FFA). As the environmental safety and health concerns arise, the use of "solvent-free" extraction is highly warranted. Current study investigated ultrasound-assisted aqueous extraction (UAAE) of low FFA-virgin avocado oil. Response surface methodology with the Box-Behnken design was used to optimize the experimental variables, namely sonication time (10-30 $\mathrm{min})$, sonication temperature $\left(20-40{ }^{\circ} \mathrm{C}\right)$, and water-to-powder ratio $(4-6 \mathrm{~mL} / \mathrm{g})$ on the responses of oil recovery and FFA. Best-fitting models with backward elimination of the multiple linear regression were generated for the responses of oil recovery $(R 2=0.9092$, $\mathrm{p}<.0001)$ and FFA $(\mathrm{R} 2=0.9799, \mathrm{p}<.0001)$. The optimum UAAE parameters to produce the highest recovery of low FFA virgin avocado oil were $6 \mathrm{~mL} / \mathrm{g}$ of water-to-powder ratio, 30 min of sonication time, and $35^{\circ} \mathrm{C}$ of sonication temperature. The oil recovery and FFA level of virgin avocado oil under these optimum conditions were 72.79 and $0.297 \%$, respectively. Compared to Soxhlet-extracted avocado oil, virgin avocado oil was lighter in color and contained a higher level of unsaturated fatty acids.
\end{abstract}

Keyword: Virgin avocado oil; High nutritional value; Free fatty acids (FFA) 